\title{
A NOÇÃO DE JUSTIÇA NO TRÂNSITO NA PERSPECTIVA DE UMA ADOLESCENTE DO ENSINO MÉDIO DA REDE PÚBLICA DE PORTO ALEGRE: UM ESTUDO PRELIMINAR COM BASE NA TEORIA PIAGETIANA
}

\author{
Taciana Brito de Moura1 \\ Maria Luiza Rheingantz Becker ${ }^{2}$
}

\section{Resumo}

Este artigo apresenta um estudo de caso que investiga a noção de justiça no trânsito presente nas respostas de uma adolescente do ensino médio da rede pública de Porto Alegre à uma entrevista realizada como estudo piloto para uma pesquisa de mestrado. $\mathrm{O}$ estudo é realizado com base na teoria piagetiana por sua relevância para as pesquisas sobre desenvolvimento moral na atualidade. A metodologia utilizada foi um roteiro de entrevista inspirado no Método Clínico de Jean Piaget. Destaca-se o processo de elaboração deste instrumento, que conta, dentre outros recursos, com dilemas elaborados a partir de histórias fictícias sobre o tema investigado. Após a realização de estudos pilotos, os resultados mostram que o roteiro de entrevista está adequado para ser aplicado aos casos múltiplos da referida pesquisa de mestrado. Quanto à noção de justiça presente nos argumentos apresentados neste estudo de caso, verifica-se que transitam entre as noções de justiça retributiva e distributiva, com maior incidência na justiça distributiva. Dessa forma, infere-se que as respostas apresentam descentração e reflexão compatíveis com a transição da heteronomia para a autonomia e da transição entre a ênfase na igualdade para a busca de equidade no juízo moral. Os dados analisados são esclarecedores para a compreensão da trajetória do pensamento da adolescente investigada, abrindo possibilidades de análise para os casos múltiplos e pesquisas futuras. Espera-se que esses resultados contribuam

\footnotetext{
1 Mestranda em Educação pelo Programa de Pós-Graduação em Educação da Universidade Federal do Rio Grande do Sul. (PPGEDU/UFRGS). Licenciada em Pedagogia (FAPA/RS). Especialista em Informação Científica e Tecnológica com Ênfase na Saúde (GHC-RS/FCC-RJ). E-mail: tacibmoura@gmail.com

2 Psicóloga pela Pontifícia Universidade Católica do Rio Grande do Sul (PUC/RS); Especialista em Educação pela Universidade Federal do Rio Grande do Sul (UFRGS), Doutora em Educação pelo Programa de PósGraduação em Educação (PPGEdu) da UFRGS. Atualmente é Professora Titular do Departamento de Estudos Básicos (DEBAS) da Faculdade de Educação (FACED) da UFRGS e Coordenadora do Núcleo de Estudos sobre a Coordenação das Ações e o Ensinar e Apreender - NECAEA, no CNPq e na FACED/UFRGS. Atua nos cursos de licenciatura, na graduação, e na Linha de Pesquisa: aprendizagem e ensino, no PPGEdu/UFRGS. E-mail: beckermarialuiza@gmail.com
} 
para o debate sobre a temática abordada e sobre as possibilidades de aprendizado e utilização das contribuições do Método Clínico na pesquisa qualitativa com entrevistas.

Palavras Chave: Noção de Justiça. Desenvolvimento Moral. Adolescente. Trânsito.

\author{
THE NOTION OF FAIRNESS IN TRAFFIC FROM THE POINT \\ OF VIEW OF A SECONDARY SCHOOL STUDENT FROM A \\ PUBLIC SCHOOL IN PORTO ALEGRE: A PRELIMINARY \\ STUDY BASED ON THE PIAGETIAN THEORY
}

\begin{abstract}
This paper presents a case study that investigates the notion of fairness in traffic contained in answers provided by a female secondary school student from a public school located in Porto Alegre (Rio Grande do Sul, Brazil) to an interview carried out as a pilot study for a Master's research. The study is based on the Piagetian theory due to its relevance to investigating moral development today. The methodology used involved an interview script inspired by Jean Piaget's clinical method containing dilemmas based on fictional stories about the topic in question, among other resources. After carrying out pilot studies, the results showed that the interview script was appropriate to the multiple case investigation for the aforementioned Master's research. The notion of fairness perceived in the arguments presented by this case study oscillates between retributive and distributive justice, with higher incidence of distributive justice. It is possible to suggest that the answers provided by the teenager show a degree of decentralization and reflection that corresponds to the transition from heteronomy to autonomy and from the focus on equality to the pursuit of equity in the moral judgement. The data analyzed helped understand the teenager's thinking process, encouraging the use of such analysis for the multiple case investigation and future researches. We hope that the results presented here will contribute to the debate on learning possibilities and the notion of fairness in traffic, as well as to using interviews based on the clinical method in qualitative researches.
\end{abstract}

Keywords: Notion of Fairness. Moral Development. Teenager. Traffic.

Volume 11 Número 2 - Ago-Dez/2019

www.marilia.unesp.br/scheme 


\section{Sthème \\ Revista Eletrônica de Psicologia e Epistemologia Genéticas}

\section{Introdução}

Este artigo traz uma contribuição para os debates sobre o desenvolvimento da noção de justiça em adolescentes através da apresentação de um estudo preliminar de uma pesquisa de mestrado desenvolvida no Programa de Pós-Graduação em Educação (PPGEDU) da Universidade Federal do Rio Grande do Sul (UFRGS).

A referida dissertação - realizada na linha de pesquisa Aprendizagem e Ensino - tem como objetivo investigar a noção de justiça no contexto do trânsito urbano em adolescentes do ensino médio de Porto Alegre. O interesse pela temática envolve a qualificação do trabalho educativo realizado por uma instituição pública que tem, dentre outros objetivos, educar para o trânsito a fim de contribuir para a redução da acidentalidade. Diante do cenário atual de trânsito, o jovem encontra-se entre os públicos mais vulneráveis. Em 2018, o Rio Grande do Sul somou 1670 vítimas fatais no trânsito. Desse total, 157 estavam na faixa entre 11 e 20 anos, sendo 11 na condição de pedestres, 38 como passageiros, 64 como motociclistas (15 antes dos 18 anos), 15 como condutores, 14 como ciclistas e 17 na carona da moto (DETRAN/RS) ${ }^{3}$.

Dentre pesquisadores do comportamento humano no trânsito, Jorge e Martins (2013) apontam que os principais fatores de vulnerabilidade do jovem estão relacionados ao seu estilo de vida e dizem respeito à condução precoce, inexperiência, tendência a subestimar o risco, distração e não cumprimento das leis. Corrobora-se os autores; porém, entende-se que, para compreender melhor a relação "perigosa" entre jovens e trânsito é importante transcender sua visão como condutores, uma vez que os próprios dados mostram sua vulnerabilidade quando investidos em outros papéis. Acredita-se que, dentre outras questões, a

\footnotetext{
3 Informação disponível em: <https://detran-admin.rs.gov.br/upload/arquivos/201906/18093022-diagnostico-acidentalidade-dez-18.pdf>. Acesso em: 20 ago. 2019.
} 


\section{Sthème \\ Revista Eletrônica de Psicologia e Epistemologia Genéticas}

dificuldade em compreender os riscos inerentes ao trânsito e a falta de discussão e reflexão sobre o tema na família e na escola também estejam entre razões dessa vulnerabilidade.

Ao buscar subsídios para a compreensão da relação entre adolescente e trânsito, especialmente no estudo de sua noção de justiça nesse contexto, tomou-se por base os estudos de Piaget acerca do desenvolvimento moral. La Taille (1994 in Piaget 1932/1994) defende, no prefácio, que a obra O julgamento moral na criança, publicada originalmente em 1932, abriu precedente para reflexões sobre moralidade humana, o que pesquisadores da época não se aventuravam a fazer. Segundo o autor, é fundamental, para entender essa obra, que leitores e pesquisadores tenham clareza de que, para entender o pensamento adulto, Piaget $(1932 / 1994)^{4}$ estudou a moralidade infantil através da observação de como crianças operam com as regras ${ }^{5}$ (processo evolutivo da prática para a consciência da regra).

Nesse contexto, Piaget (1932/1994) estudou, paralelamente ao desenvolvimento moral, a construção da noção de justiça na infância, pois constatou, nas respostas das crianças, que desde muito cedo a forma como elas entendem o justo e o injusto tem relação estreita com as etapas de moralidade diferenciadas pelo autor, quais sejam anomia, heteronomia e autonomia. Para a investigação da noção de justiça, o teórico considerou o tipo de respeito envolvido nas relações entre a criança e o meio e a forma como ela interpreta a responsabilidade e as sanções, distinguindo três noções de justiça: imanente, retributiva e distributiva.

\footnotetext{
4 Para esclarecer o leitor sobre o período em que foi publicada a obra original citada, este artigo fará sempre referência às duas datas: original/obra lida.

5 Regra, segundo La Taille (2013), é aquilo que devemos ou não fazer. Não há regras para tudo e as que existem nos dizem "como" agir, mas não "por que" devemos agir de tal maneira. Essas limitações são superadas pelos princípios implícitos nas regras, que nos auxiliam a compreender em nome do que devemos agir.
}

Volume 11 Número 2 - Ago-Dez/2019

www.marilia.unesp.br/scheme 
Dentre os estudiosos que destacam a relevância dos estudos piagetianos sobre a moral, Kesselring (1993, p. 173, grifo do autor) afirma que "vale a pena mencionar e discutir os temas mais importantes nele [O juízo moral na criança] tratados" pela forma como Piaget estudou a compreensão das regras em diferentes etapas da vida, observando e questionando crianças francesas enquanto jogavam bola de gude. Para o autor, os estudos piagetianos elucidam como a criança se desenvolve moralmente passando das regularidades naturais para a compreensão das normas sociais.

Freitas (2002) ressalta a importância dos estudos de Piaget sobre a moral, especialmente no que se refere ao desenvolvimento da autonomia. A autora lembra que, embora O juízo moral na criança seja uma das obras mais conhecidas do autor, é importante considerar o conjunto de sua obra para a compreensão do conceito de autonomia moral e da responsabilidade da educação na construção de sujeitos intelectual e moralmente autônomos.

Para La Taille (2016), o foco da obra citada está na descoberta de que o desenvolvimento cognitivo é paralelo ao afetivo e que a moralidade se desenvolve nesses dois planos, ao longo de toda a vida. Por sua riqueza de conhecimentos, a obra (reeditada em 1994) ainda inspira pesquisadores contemporâneos que buscam compreender o desenvolvimento humano em diferentes contextos, tal como esta autora.

O destaque dado neste artigo a um estudo preliminar diz respeito aos passos seguidos na elaboração de um roteiro de entrevista para a pesquisa e, também, ao alcance da reflexão da jovem participante ao ser instigada por questões sobre o tema. Ela demonstrou interesse em discuti-lo, e seus argumentos foram detalhados, coerentes e compatíveis com o respeito mútuo em grande parte, corroborando os estudos de Piaget (1932/1994), que identificou nas concepções dos 


\section{Sthème \\ Revista Eletrônica de Psicologia e Epistemologia Genéticas}

adolescentes com os quais trabalhou sobre a noção de justiça, indícios de reciprocidade e respeito mútuo. La Taille (2016) traz um dado interessante para este estudo quando destaca que os jovens de suas pesquisas elegeram a responsabilidade e a justiça como as qualidades mais relevantes para o ser humano conviver em sociedade. Esse dado demonstra que há jovens na atualidade interessados em refletir sobre questões sociais.

O estudo de caso será apresentado a partir dos seguintes tópicos: a noção de justiça em adolescentes; procedimentos metodológicos; apresentação e análise dos resultados e considerações finais.

\section{A noção de justiça em adolescentes}

Nos estudos piagetianos sobre a moralidade, é importante destacar que há uma etapa anterior ao respeito denominada pelo teórico como anomia, na qual inexiste qualquer sentimento moral ou de justiça. Essa etapa condiz com o primeiro período de desenvolvimento da inteligência sensório-motora (PIAGET, 1953/2014) ${ }^{6}$, na qual sentimentos intraindividuais como prazer e dor, satisfação e insatisfação, permeiam as relações do sujeito com o meio de modo egocêntrico, importando somente a satisfação de suas necessidades.

A seguir, novas relações com o meio auxiliam a criança a deixar de ser o centro do mundo e a ultrapassar a etapa de anomia; "a pessoa do outro adquire um valor particular; não interferem mais simplesmente os afetos ligados ao sucesso momentâneo dos contatos". (PIAGET, 1953/2014, p. 146). No campo cognitivo e moral, passa a desenvolver-se, concomitantemente, a inteligência verbal e prática, que possibilita a socialização e a elaboração de conceitos pela criança,

\footnotetext{
6 Para esclarecer o leitor sobre o período em que foi publicada a obra original citada, este artigo fará sempre referência às duas datas: original/obra lida.
}

Volume 11 Número 2 - Ago-Dez/2019

www.marilia.unesp.br/scheme 


\section{Şchème \\ Revista Eletrônica de Psicologia e Epistemologia Genéticas}

ainda sem reversibilidade (estágio pré-operatório). Há, então, nesse pensamento ainda egocêntrico, a interação da criança com o mundo a partir de um realismo moral ${ }^{8}$ que a dificulta descentrar-se e coordenar pontos de vista além do seu.

Essa nova forma de pensar e se relacionar com o meio dá início ao que Piaget (1932/1994, 1953/2014) identifica como heteronomia moral. Nessa etapa, a criança considera o cumprimento incondicional das regras do seu meio. As relações interindivuais transcorrem com base no respeito unilateral e sentimentos como medo ou amor em relação ao adulto, tipificando uma relação de coação do adulto para a criança. Predomina, nessa etapa, a heteronomia e a justiça retributiva, na qual é justo aquele que cumpre as regras e injusto aquele que não as cumpre, necessitando ser punido por suas faltas.

Como está subjugada à realidade material, a criança tende à equivalência em seus julgamentos. A responsabilidade é avaliada objetivamente, considerando a materialidade do ato, ou seja, é mais culpado aquele que causou o prejuízo maior, mesmo que não tenha sido intencional, e a sanção deve ser proporcional ao prejuízo, ainda que não tenha relação com a ação praticada. Essas sanções são chamadas expiatórias por terem origem na autoridade. Quando dominantes na educação, essas relações podem prejudicar o desenvolvimento do sentimento de justiça no sentido do respeito mútuo e da cooperação.

\footnotetext{
7 Transformações no campo da lógica possibilitam à criança operar através de estruturas organizadas de conjunto que, em um segundo nível, possibilitará a reversibilidade do pensamento, ou seja, a realização do inverso da operação, tanto no plano concreto quanto abstrato. No plano afetivo, possibilita ao sujeito coordenar outros pontos de vista além do próprio. (PIAGET, 2007; 2014).

8 Realismo refere-se ao fato de a criança "considerar como coisas (como objetos exteriores), à 'coisificar' os conteúdos de sua consciência". (PIAGET, 1932/1994, p. 147). Assim, realismo moral é a tendência da criança pequena, quando começa a decodificar as normas do seu meio, em considerá-las existentes em si, portanto, não generalizáveis, nem modificáveis, devendo ser obedecidas incondicionalmente. (PIAGET, 1932/1994). Desse ponto em diante, a criança percorre um longo caminho até compreender que a norma é construída socialmente.
}

Volume 11 Número 2 - Ago-Dez/2019

www.marilia.unesp.br/scheme 
Há, ainda, outra noção de justiça que condiz com a moral heterônoma e está relacionada a presença de punições. Trata-se da justiça imanente, na qual a criança pequena acredita que as regras sociais são como as leis físicas e, portanto, há sanções que são "automáticas, que emanam das próprias coisas". (PIAGET, 1932/1994, p. 192). Para esse ponto de vista, tudo que acontece no universo é regido por leis naturais e físicas e tem um propósito, independentemente da ação humana. Assim como sol e lua se movem, o dia sucede a noite, um sofrimento decorrente de um choque elétrico pode, na concepção da criança, ser um castigo divino ou da natureza por uma falta cometida. Segundo o autor, tal crença tenderá a dar lugar a outros julgamentos, conforme a criança cresça e se desenvolva no sentido da reciprocidade e cooperação. Também é possível que a crença na justiça imanente persista ao longo da vida sem causar maiores dificuldades.

Ao mesmo tempo que a criança se relaciona com adultos de forma heterônoma e com outras crianças, especialmente ao ingressar na escola, sentimentos como solidariedade e justiça vão se desenvolvendo. Dessa convivência com pares, na qual o respeito mútuo vai se construindo até passar a ser a base de suas relações, inicia-se a construção da autonomia, tornando-se evidente a presença do sentimento de igualdade nas relações.

Na autonomia moral, a tendência é que o indivíduo passe a refletir e questionar mais a realidade, relativizar o certo e o errado, julgar de acordo com sua escala de valores (sua consciência) e não aceitar a verdade imposta como absoluta. Nessa fase, ele tende a ser mais crítico, podendo, inclusive, questionar regras vigentes e criar as próprias regras. Quanto mais autônomo, menos a coação 
deixa de ter efeito sobre o indivíduo e mais o respeito passa a ter por base a reciprocidade. ${ }^{9}$ (PIAGET, 1932/1994, 1953/2014).

Aos poucos, a justiça distributiva vai se construindo. A busca de igualdade vai dando espaço à busca de equidade nas relações, que, consequentemente, tendem a ser mais justas. As crianças maiores entendem a responsabilidade a partir das intenções, acreditando na punição como medida preventiva e na sanção por reciprocidade como a mais justa nesse sentido. Em qualquer idade, podem ser encontradas as duas formas de interpretação das sanções, e a tendência é que o sujeito evolua da expiação para a reciprocidade de forma gradual, conforme o desenvolvimento da noção de justiça. Segundo Piaget (1932/1994, p. 170), “quanto mais o jovem se desenvolve moralmente mais condições de compreender o valor das medidas por reciprocidade".

Sales (2000) corrobora Piaget (1932/1994) sobre o avanço da responsabilidade a partir da proporcionalidade e da intencionalidade. Ao utilizar dilemas para verificar o que crianças e adolescentes pensam sobre determinadas condutas escolares, tais como se é certo ou errado dar a mesma nota para quem cumpre e quem não cumpre o prazo de entrega de um trabalho, a autora viu que a avaliação da responsabilidade avança dos resultados materiais ou da conformidade com as regras para a avaliação das intenções.

Guedes e Pascual (2016), também com o auxílio de dilemas, preocuparam-se em estudar se, ao participarem da mediação de conflitos escolares, alunos adolescentes, que frequentemente se envolvem nesses conflitos, têm alguma mudança em seu julgamento moral. Concluíram que a técnica de mediação de con-

\footnotetext{
9 "Reciprocidade é a coordenação mútua das atitudes e dos pontos de vista, tanto afetivos como cognitivos." (PIAGET, 1953/2014, p. 71).
} 


\section{Sthème \\ Revista Eletrônica de Psicologia e Epistemologia Genéticas}

flitos utilizada pela escola que serviu de contexto para tal pesquisa não oportunizou a mudança de ponto de vista nos alunos, cujas respostas incidiram sobre a heteronomia moral. Prevaleceu nas respostas a obediência à autoridade, o respeito às regras escolares e o castigo nos casos de transgressão.

Os estudos piagetianos sobre desenvolvimento moral mostram que, mesmo atingindo um pensamento mais autônomo, não há garantia de conduta moral. Porém, acredita-se que, quanto mais desenvolvida a moral da autonomia, mais frequentes serão as condições de reflexão diante de situações nas quais estejam em jogo escolhas morais. Assim, aumentam as chances de cooperação social $^{10}$, de desenvolvimento do igualitarismo e da equidade (que garante que a justiça prevaleça aos interesses individuais ou de pequenos grupos), seja no trânsito, na escola ou demais espaços coletivos.

Pesquisadores como Dell' Aglio e Hutz (2001), Sampaio, Camino e Roazzi (2007) e Menin, Bataglia e Moro (2013) também estudaram os princípios de justiça em crianças e adolescentes e encontraram tendências ao igualitarismo em crianças menores e à equidade nas maiores, corroborando os estudos de Piaget (1932/1994). Através de histórias elaboradas para esse fim, constataram que as respostas dos sujeitos investigados encontravam-se em diferentes níveis de noção de justiça e que a descentração era mais evidente em adolescentes do que em crianças pequenas, aproximando-os da justiça distributiva.

Mesmo que a noção de justiça distributiva em nível mais elevado seja esperada em crianças mais velhas e adolescentes, Menin, Bataglia e Moro (2013)

\footnotetext{
10 Piaget (1973, p. 182): “cooperação social é [...] um sistema de ações, ações interindividuais e não simplesmente individuais, mas ações mesmo, e consequentemente submetidas a todas as leis que a caracterizam". Assim, pode-se inferir que a cooperação social diz respeito a mobilização de esforços individuais em prol de objetivos comuns.
} 
e Schünemann et al. (2016) encontraram, em menor número, respostas contemplando a equidade também em crianças menores. Para Piaget (1932/1994), existe, ao longo das idades, uma evolução da concepção de justiça retributiva para a concepção de justiça distributiva, embora deva-se relembrar que a idade cronológica não é um fator determinante do desenvolvimento na sua teoria. Menin, Bataglia e Moro (2013) identificaram, também, que, em determinadas situações, os adolescentes não atingiram o nível mais elevado em termos de concepções de justiça, estando ainda presos, como as crianças menores, às coações de autoridades.

Para atingir um nível mais elevado de noção de justiça são necessários avanços cognitivos que possibilitem o raciocínio hipotético dedutivo sobre proposições verbais (operações formais), bem como transformações afetivas que possibilitem o desenvolvimento da reciprocidade e do respeito mútuo não só nas relações afetivas, mas também nas relações externas ao grupo social ao qual o adolescente pertence. Essa evolução implica avanços na descentração e na autonomia intelectual e moral. Para Piaget (1953/2014), é a descentração que possibilita avanços no sentido de diferenciação e coordenação de pontos de vista.

Para Freitas (2003), ao ampliar seu universo, ultrapassando os limites do real, o jovem descobre que existe um coletivo maior que aquele do seu contexto familiar ou de amigos e começa a operar com um conjunto de valores diferente daquele que estava acostumado, passando a desenvolver ideais de solidariedade e de justiça que considerem sociedades mais amplas, como a do país ou 


\section{Şchème \\ Revista Eletrônica de Psicologia e Epistemologia Genéticas}

da nação. Nesse sentido, respeitar os outros significa ter simpatia ${ }^{11}$ para com outrem, legitimar seu ponto de vista, avaliar e ajuizar considerando aquilo que é importante para o outro, e não somente para si.

Importante ressaltar que não há uma ruptura na qual o respeito unilateral dê lugar ao respeito mútuo como em um passe de mágica, pois os dois respeitos podem coexistir em uma mesma pessoa ao longo de toda a vida, assim como as duas morais, do dever e do bem. A predominância de um respeito sobre o outro vai depender do quão evoluída moralmente ela estiver e da situação ou problema que se apresentar. La Taille (2016, p. 33) relembra que “Piaget já afirmava que, na maioria dos seres humanos, costuma prevalecer a heteronomia, que convive com algumas 'ilhas' de autonomia". Portanto, entende-se que, mesmo que seja mais provável encontrar na sociedade contemporânea adolescentes com um pensamento voltado para a noção de justiça retributiva, há possibilidade de jovens apresentarem juízos característicos da justiça distributiva, como mostram as pesquisas apresentadas, mesmo que sofram influência de uma realidade com tantos problemas morais e falta de valores como a contemporânea.

Neste estudo, admite-se, com Piaget (1932/1994, 1953/2014) e com as pesquisas anteriormente apresentadas, que é possível a construção de juízos com uma moral autônoma por adolescentes e que eles considerem o ponto de vista do outro e se preocupem em cooperar em uma perspectiva social descentrada. $\mathrm{O}$ caso a ser apresentado explicita o ponto de vista de uma jovem sobre justiça no

\footnotetext{
11 Piaget (1973, p. 114-163) coloca que como existe um número elevado de escalas de valores em uma sociedade, as incoerências são mais comuns que as concordâncias. Assim, há simpatia entre indivíduos quando um satisfaz o outro. Complementando essa ideia, Piaget (1953/2014, p. 160) diz o seguinte sobre a simpatia: "[...] condição básica de toda simpatia [...] que, na simpatia intervenham elementos de valorização, isto é, que cada indivíduo, em uma troca afetiva a dois, valoriza, aprecia as razões do outro, as situações e os objetos. Em outras palavras, no momento da troca, cada indivíduo avalia sem cessar em função daquilo que chamaremos, para simplificar, uma escala de valores". Assim, pode-se inferir que, quando a valorização é recíproca, as escalas de valores entre duas pessoas ou mais possuem elementos em comum, o que para o autor é fundamental para que se constituam as coletividades.
}

Volume 11 Número 2 - Ago-Dez/2019

www.marilia.unesp.br/scheme 


\section{Sthìme \\ Revista Eletrônica de Psicologia e Epistemologia Genéticas}

trânsito, no qual há, em boa parte das respostas, a presença de sentimentos como solidariedade e respeito mútuo, indispensáveis na autonomia moral.

\section{O delineamento do estudo}

Para a realização do estudo de caso (YIN, 2015), considerou-se que o problema de pesquisa está mais relacionado ao "como" do que ao "por que", uma vez que a intenção é compreender como a adolescente interpreta as relações interpessoais no trânsito urbano e as diferencia entre relações justas ou injustas. A análise do caso realizada não é exaustiva, tendo por foco a compreensão da noção de justiça pela jovem e o roteiro básico, elaborado para a entrevista a partir da perspectiva piagetiana. Trata-se de um estudo preliminar, que antecipa estudos de casos múltiplos a serem desenvolvidos na dissertação.

O contexto da investigação, como já foi dito, é o das relações interpessoais no espaço de trânsito urbano, recortadas dentre as diferentes ordens de problemas que caracterizam esse espaço atualmente. Acredita-se que questões morais e éticas estão implícitas nos acontecimentos do cenário atual e destaca-se, neste trabalho, a escolha de duas dimensões para abordá-las.

A primeira dimensão considera o fato de que, mesmo com um complexo sistema de regras instituído para a manutenção da ordem e da justiça, sendo o Código de Trânsito Brasileiro (CTB) a lei principal, o trânsito apresenta elevadas estatísticas de infrações e acidentalidade, tornando-se arriscado e violento. Diante disso, é possível inferir que seus partícipes não estão respeitando efetivamente as normas para a garantia de segurança. A segunda dimensão pondera que o trânsito, assim como a escola e outros espaços de convivência, nem sempre conta com pessoas conscientes de seus direitos, deveres e responsabilidades e acaba se tornando um espaço de relações com muitos conflitos e injustiças. 
Para Corassa (2011, p. 88), o trânsito é um dos espaços mais democráticos que existem, na medida em que nele circulam "o rico e o pobre, o letrado e o analfabeto, a pessoa com sua religião e o ateu [...] Distingue-se de outros espaços em que as pessoas se agrupam por algum tipo de afinidade". Por toda essa diversidade, entende-se que as relações interpessoais e, nelas, o respeito mútuo, são fundamentais para a convivência urbana.

A escolha do caso deu-se entre jovens que vivenciam espaços educacionais favoráveis à reflexão sobre o tema. Convidou-se uma adolescente de 18 anos que frequenta o Ensino Médio noturno de uma escola pública da zona norte de Porto Alegre e cumpre estágio de 6 horas em uma instituição, também pública, que inclui entre seus objetivos educar para um trânsito seguro. Foram observados os procedimentos éticos, conforme orienta a Resolução 510/16 do CONEP, que versa sobre a ética em pesquisas com seres humanos, tais como a preservação de sua identidade, com o nome fictício de Sol; a informação sobre os objetivos da pesquisa; sobre a participação voluntária e a possibilidade de desistir de participar a qualquer momento. A formalização do aceite foi realizada através da assinatura do Termo de Consentimento Livre e Esclarecido.

O instrumento da investigação é a entrevista semiestruturada, inspirada no método clínico de Jean Piaget. (DELVAL, 2002). Tal recurso viabiliza o processo ativo da autora ao explorar o pensamento da adolescente, admitindo intervenções conforme o andamento da conversa. Para uma abordagem adequada à faixa etária juvenil, que tornasse possível acessar o pensamento da adolescente e que a instigasse a ir além do senso comum e de respostas prontas, o roteiro de entrevista conta com o apoio de histórias fictícias com dilemas sobre o tópico em estudo, tal como fez Piaget (1932/1994) no estudo da noção de justiça em crianças, ressalvadas as adequações à faixa etária. 
Segundo Delval (2002), a utilização de histórias como apoio à entrevista auxilia o sujeito no entendimento da questão, permitindo que ele se coloque na situação e não se sinta constrangido ao se posicionar, uma vez que julga ações fictícias. Nos últimos vinte anos, autores como Sales (2000), Dell'Aglio e Hutz (2001), Sampaio, Camino e Roazzi (2007), Menin, Bataglia e Moro (2013), Schünemann et al. (2016) e Guedes e Pascual (2016) também utilizaram histórias em suas pesquisas com crianças e adolescentes acerca da noção de justiça, o que incentivou a adoção dessa estratégia. Acredita-se que os Dilemas favorecem ao jovem colocar-se em diferentes perspectivas e avaliar mais livremente a situação, uma vez que se trata de situações e personagens fictícios.

O roteiro elaborado para a entrevista conta com 10 questões iniciais que têm por finalidade abrir espaço ao diálogo com o jovem, conhecer um pouco de sua rotina, deslocamentos diários e relação com o trânsito. A seguir, constam 02 Dilemas, 10 afirmações sobre decisões e atitudes em situações de trânsito para juízo de justiça (Rapidinhas) e 03 ditados populares sobre relações interpessoais para busca de suas implicações no contexto do trânsito.

Os Dilemas foram elaborados pela autora: o primeiro, intitulado “Dilema do calçadão", traz a história de um menino que se desloca de bicicleta para buscar um remédio para a febre da irmã pequena, a pedido da mãe, e depara-se com duas possibilidades de trajeto: uma ciclovia (mais longo) e um calçadão exclusivo para pedestres (mais curto). O segundo, "Dilema da vaga prioritária", aborda a situação de uma jovem desempregada que, ao chegar atrasada no local onde vai participar de uma entrevista de emprego, depara-se com uma única vaga para estacionar seu veículo, mas trata-se de uma vaga prioritária. Diante da possibilidade de escolha proporcionada pelos dilemas, espera-se que o adoles- 
cente se posicione sobre as condutas dos personagens, apresentando justificativas que auxiliem na compreensão do que é justo ou injusto para ele e da necessidade de sanção diante do exposto.

Outro recurso elaborado para a entrevista foi denominado "Rapidinha das ações justas ou injustas no trânsito". A Rapidinha, como será chamada no decorrer do artigo, foi elaborada em Power Point, contendo imagens extraídas da internet com cenas frequentemente observadas no trânsito como o de Porto Alegre e sua narrativa ao lado. São dez situações elaboradas aos pares, contrapondose no sentido de apresentarem a conduta infratora de um lado e quem sofre com a infração do outro. Por exemplo: "Um amigo avisou no grupo do WhatsApp sobre uma blitz de trânsito" tem como contraponto, em determinado momento, "Um jovem bêbado foi pego na Balada Segura". Dessa forma, espera-se possibilitar que o jovem se posicione a partir de diferentes pontos de vista, reflita sobre as questões propostas e apresente suas razões ao considerar as atitudes justas ou não, bem como verificar a coerência das respostas quando comparados ponto e contraponto.

Ao final, inclui-se no roteiro três ditados populares sobre os quais é possível fazer inferências à noção de justiça relacionada ao contexto de trânsito. São eles: "o que vale é a intenção", "para amigos tudo e para desconhecidos a lei" e "não faça aos outros o que não queres que façam a ti". A intenção é instigar que o jovem relacione tais ditados às situações de trânsito apresentadas nos Dilemas e na Rapidinha e reflita sobre as relações interpessoais nelas contidas.

A entrevista seguiu orientações de Delval (2002) quanto ao planejamento de condições favoráveis à obtenção dos melhores resultados. Nesse sentido, optou-se pela sala de reuniões da referida instituição pública, por ser um local tranquilo e sem interrupções. A conversa foi gravada com o consentimento 


\section{Sthème \\ Revista Eletrônica de Psicologia e Epistemologia Genéticas}

da jovem e teve uma duração de 40 minutos. A realização de entrevista baseada no Método Clínico não é uma técnica simples, pois requer do pesquisador certa habilidade para que a conversa não fique centrada apenas no roteiro, mas abra possibilidades para contra argumentações.

\section{Apresentação e análise dos dados}

Passa-se à apresentação e análise dos argumentos mais relevantes presentes nas respostas de Sol ao longo da entrevista a fim de verificar quais noções de justiça estão presentes nessas respostas. Como ponto de partida, foram definidos dois temas principais na categorização das respostas para representar o conjunto de ideias sobre a temática investigada. O primeiro foi "O respeito mútuo como condição para a justiça no trânsito", respondendo aos subtemas a) ponto de vista inicial sobre o contexto de trânsito e b) capacidade de coordenar diferentes pontos de vista nas situações de trânsito propostas. O segundo foi “ A importância das normas para segurança e justiça no trânsito", discorrido nos subtemas a) compreensão sobre a importância das normas de trânsito e b) a sanção por multa como instrumento de justiça no trânsito.

\section{O respeito mútuo como condição para a justiça no trânsito}

Considerando-se as contribuições de Piaget (1932/1994, 1953/2014) acerca do desenvolvimento moral, atitudes justas no trânsito, para este estudo, são aquelas nas quais as pessoas se relacionam com base no respeito mútuo, agindo em benefício da coletividade, e injustas são aquelas nas quais as pessoas buscam a satisfação de interesses individuais. Entende-se que a descentração desempenha papel fundamental no processo evolutivo da jovem, auxiliando-a a considerar outros pontos de vista além do próprio. Nesse sentido, busca-se verificar o quão descentradas são as respostas da adolescente investigada. 
a) Ponto de vista inicial sobre o contexto de trânsito:

Pretende-se, com esse subtema, compreender o ponto de vista inicial de Sol sobre o contexto de trânsito no que tange à própria experiência, nos deslocamentos diários. A jovem descreve o trânsito como um espaço violento e elenca fatores como falta de segurança, de infraestrutura, de organização e de respeito entre as pessoas que, além de mal-educadas, "são estressadas" e "descontam seus problemas" no trânsito. Ela relata que são poucos os dias em que não presencia conflitos em seus deslocamentos. Segue extrato elucidativo selecionado a partir das questões iniciais:

Entrevistadora: O que tu achas que leva a pessoa a contribuir para esses conflitos no trânsito?

Sol: [...] alguma coisa pode ter afetado ela, tipo ter brigado em casa antes de sair, que pode ter causado um atraso, aí chega lá no trânsito e desconta nas outras pessoas, envolvendo, muitas vezes, quem não tem nada a ver com a história. Vejo muito isso. E é um perigo, porque às vezes dá até morte. Mas também tem aquelas pessoas mal-educadas mesmo, que não estão nem aí pros outros.

Para a jovem, as pessoas são capazes de tornar o trânsito "mais arriscado do que já é" com suas condutas erradas. Diz que sente na própria pele o medo dos outros ao deslocar-se de carona com o pai "por causa da falta de respeito dos motoristas com os que andam de moto", enfatizando que "é muito injusto o tratamento dado aos motociclistas no trânsito". Sobre essa questão, destaca-se o seguinte argumento:

Sol: [...] os carros e o ônibus às vezes não respeitam os motociclistas. [...] meu pai já me trouxe para o trabalho de moto, e eles fazem de propósito, pra dar aquele sustinho. Eu acho certo passar pelo corredor [motociclistas 
entre os carros], se tá livre pode, só que eles [motoristas de ônibus] trocam de pista bem na hora [...] parece que fazem de propósito. Isso é muito injusto.

A resposta considera apenas o ponto de vista de um determinado grupo no trânsito, os motociclistas, como vítimas das atitudes dos demais, o que dificulta a coordenação de outras perspectivas. O fato de um familiar estar pilotando a moto pode ser um fator relevante na dificuldade em considerar o ponto de vista de outros usuários da via. Nesse caso, a afetividade está voltada para sentimentos interindividuais de um determinado grupo (motociclistas) e não para sentimentos relativos à consciência coletiva. (PIAGET, 1953/2014).

b) Capacidade de coordenar diferentes pontos de vista nas situações de trânsito propostas:

O roteiro de entrevista e sua condução possibilitaram verificar, nas respostas de Sol, o modo como ela coordena diferentes perspectivas quando se trata de avaliar a convivência entre partícipes do trânsito urbano, bem como as tendências envolvidas em suas concepções. Inicia-se apresentando a resposta à Rapidinha que questiona se é justo uma mãe estacionar e obstruir a rampa de acesso à calçada próxima ao mercado para não deixar o filho sem leite, uma vez que o mercado está prestes a fechar:

Sol: É injusto. Porque não existe só um mercado para comprar o leite [risos]. Ela pode comprar em outro lugar. Por que tem que parar justo onde as pessoas precisam subir?

Entrevistadora: E, fazendo as compras bem rapidinho, ainda assim seria injusto? 
Sol: Não importa. Seria injusto porque não pode estacionar onde tem rampa. Imagina se chega um cadeirante? Uma pessoa com a perna quebrada? Sem noção essa mãe.

Nessa resposta, houve coordenação de perspectivas com valorização do direito ao acesso à calçada por todos os partícipes de maneira equitativa, mantendo-se o juízo favorável ao respeito mútuo e cooperação mesmo na contra argumentação. Ao defender a justiça como uma virtude moral, La Taille (2006, p. 61) traz, dentre outros exemplos de atitudes justas, que "é justo colocar nas calçadas rampas, para que as pessoas em cadeiras de rodas possam transitar tranquilamente pelas ruas". Em contrapartida, entende-se que é injusto condutores estacionarem seus veículos obstruindo tal passagem para suprir suas urgências, como ir ao banco ou ao supermercado. Por isso, elaborou-se a seguinte afirmativa, que traz o contraponto dessa ação: "o cadeirante não conseguiu acessar a calçada porque um condutor estacionou, obstruindo a rampa de acesso", que teve a seguinte resposta:

Sol: É injusto, porque a pessoa que estacionou só pensa nela e não nos outros. Deve ter sido aquela mãe que queria comprar o leite [risos]. Queria ver se fosse ela que estivesse numa cadeira de rodas, aí ela ia entender.

O argumento remete à situação já apresentada, demonstrando que há coerência entre as respostas e confirmando a tendência da jovem a pensar no bem coletivo. Porém, não se pode afirmar que, em situações análogas, o argumento tenha a mesma conotação.

Para essa discussão, destaca-se a resposta ao dilema da vaga prioritária na qual, pela interpretação de Sol, a personagem não estaciona para não arriscar ser "pega" pela fiscalização. Segue o argumento elucidativo: 
Sol: Eu não arriscaria em deixar na vaga, porque ela poderia não passar na entrevista. Teria o aluguel, a multa e o possível carro sendo guinchado se a fiscalização pegasse.

Entrevistador: Essa seria a pior consequência da atitude dela ou poderia haver outra?

Sol: Sim, mesmo que ela conseguisse o emprego [...] E se o salário não cobrisse tudo isso?

Entrevistador: Mas outro colega que entrevistei disse que a pior consequência seria chegar alguém que realmente precise dessa vaga.

Sol: Também, mas no caso dela que tá sem emprego e sem dinheiro, seria muito pior ela estacionar e levar uma multa.

Na questão anterior, que trata da obstrução da rampa de acesso, a tendência presente nos argumentos volta-se a interesses coletivos. Já no que tange à vaga prioritária, a tendência vai ao encontro do interesse individual, uma vez que não se considera, inicialmente, a possibilidade de chegar alguém com direito a ocupar a referida vaga. O ponto de vista está focado no prejuízo para a protagonista da história em caso de autuação, seguindo com o mesmo pensamento após a contra argumentação.

Os dados apresentados neste subtema apontam para duas tendências quanto à coordenação de perspectivas nas relações de trânsito: a individual e a coletiva. Na primeira, as respostas mostram um ponto de vista mais egocêntrico, voltado à satisfação de interesses pessoais. Na segunda, a visão amplia-se para o contexto das relações sociais, e os argumentos passam a considerar a perspectiva do outro no trânsito, especialmente do mais frágil, evidenciando-se uma tendência à reciprocidade e solidariedade. 
Freitas (2002, p. 20) apresenta uma ideia que se adequa ao contexto de trânsito urbano atual e tem relação com a oscilação de pontos de vista encontrados nas respostas elencadas neste tema. A autora diz que, quando predominam na sociedade interesses individuais e rivalidades, dificilmente a pessoa, por mais autônoma que seja, consegue resistir à "opinião social vigente e tampouco se deixa dominar por suas fantasias subjetivas ou desejos imediatos". Assim, ao inserir-se no trânsito, com todas as diferenças e falta de valores sociais que caracterizam esse espaço, a jovem está implicada em uma perspectiva cultural mais individualizada. Pode somar-se a esse contexto a tendência dos jovens de estarem mais centrados em seu próprio ponto de vista (egocentrismo juvenil), dificultando sua capacidade de coordenar perspectivas (PIAGET, 1953/2014) e desenvolver valores como respeito mútuo, empatia, solidariedade e justiça, tão importantes para a convivência no trânsito.

\section{Normas e sanções como instrumento de justiça no trânsito}

Entende-se, com base nos estudos de Piaget (1932/1994) sobre a prática e a consciência da regra, que o indivíduo que cumpre as normas de trânsito apenas por dever ou medo da sanção não age pensando no outro; portanto, não há sentimentos de justiça e, sim, respeito unilateral. Quando a compreensão vai além do dever legal, envolvendo o direito do outro com quem se compartilha o espaço público, a adequação à lei está embasada na reciprocidade, no respeito mútuo, na vontade de cooperar para um trânsito melhor; portanto, pode-se dizer que há busca de justiça. Nesse sentido, busca-se verificar, nos principais argumentos, como as normas são interpretadas e quais tendências estão mais presentes: a do dever puramente legal ou com base em princípios morais. 


\section{Sthìme \\ Revista Eletrônica de Psicologia e Epistemologia Genéticas}

a) Compreensão sobre a importância das normas de trânsito:

Piaget (1932/1994) afirma que a responsabilidade nasce da sanção. Portanto, a sanção é auxiliar no trânsito no sentido de procurar limitar as ações de determinados indivíduos que podem até considerar importante cumprir normas, mas, na hora de agir, não refletem sobre as consequências de suas escolhas no coletivo. La Taille (2016), ao analisar a sociedade contemporânea, diz que o “problema maior não está [...] na compreensão racional da moral. O problema maior está em seu sentido ético", ou seja, as pessoas conhecem as normas, mas não as vivenciam.

Ao discutir o conceito de justiça na era da globalização, Kesselring (2007) coloca que, para que um regramento legal ou ordenamento social sejam justos, os cidadãos envolvidos devem estar dispostos a segui-los sem pressão do governo e sem sentimentos egoístas, mas com critérios universalistas. Essa ideia vem ao encontro do que diz Piaget (1953/2014) sobre o sujeito: quanto mais autônomo, mais capaz de compreender a importância das regras sociais para o bem coletivo e obedecê-las por vontade de cooperar.

Esses argumentos corroboram o que se espera em relação às normas de trânsito, que os princípios de justiça nelas implícitos possam estar presentes na consciência dos cidadãos para auxiliar nas suas tomadas de decisão. Com base nisso, este subtema pretende analisar o quanto Sol valoriza o conjunto de normas de trânsito para o bom funcionamento de uma sociedade, mesmo não tendo consciência de todas elas. Como não foi feita uma pergunta especificamente para esse fim, busca-se o que está implícito nas respostas acerca dessa concepção. Inicia-se com o seguinte extrato:

Entrevistador: O que significa, para ti, ser uma pessoa justa no trânsito? 
Sol: Obedecer às regras! Sem dúvida! Se tem faixa de pedestre, atravessar nela [...] Que nem os carros, se é amarelo dá pra passar? Não. Espera. [...] Se o motorista vê a pessoa querendo atravessar na faixa, para, não importa se tá com pressa.

Entrevistador: Por que é importante obedecer às regras para ser justo?

Sol: Porque fazendo o que é certo tu te protege e protege os outros também [...] O motorista, quando bebe e vai pro trânsito, não pensa que pode matar gente, ele quer se divertir.

Ao evocar algumas normas, como atravessar na faixa de pedestres e respeitar o semáforo, o argumento sugere a compreensão de que é importante ter-se um regramento para a organização e segurança no trânsito e que segui-lo, mesmo diante dos impasses da vida diária, como a pressa, o desejo de se divertir ou de chegar logo ao destino, é dever de todas as pessoas.

Conforme La Taille (2006, p. 60), “todo o sistema moral contém deveres para com outrem"; portanto, as normas de trânsito, cujos objetivos estão embasados em princípios morais como solidariedade, respeito mútuo e justiça, pressupõem que os partícipes reconheçam que se trata de um espaço compartilhado, no qual o dever de cada um em cumpri-las assegura os direitos de todos.

Outro argumento que auxilia a elucidar qual a importância do regramento de trânsito na concepção da jovem, foi encontrado na resposta seguinte à questão da Rapidinha: "um amigo avisou no grupo sobre uma blitz de trânsito”. Segue o diálogo:

Sol: Vou ser bem sincera: isso já aconteceu na minha família. Não sei te dizer se é justo ou injusto. Porque, assim ó, na verdade é injusto, porque, por mais que tu queira prevenir a pessoa de ter um prejuízo, tu tá arriscando a vida de outra. Então acho que é um pouquinho injusto. 
Entrevistador: Poderias explicar melhor como pode ser um pouco injusto?

Sol: É que tu tentas ajudar, por um lado, quando é um parente ou um amigo, pra pessoa não perder tempo na blitz. Mas, por outro lado, não é justo, porque alguém pode tá bêbado e sair atropelando, passando por cima dos outros, bater de carro.

Analisa-se essa resposta juntamente com a explicação sobre o ditado popular "para os amigos tudo e para os estranhos a lei". Sobre o ditado, o argumento refere-se ao fato de que "sempre se procura proteger um parente ou amigo e, para os estranhos, vale a lei. Tipo aquela história da blitz, todo mundo vai querer ajudar um familiar". Em conjunto, as respostas convergem para a ideia de que a lei deve ser aplicada para algumas pessoas, e para outras não.

Em contrapartida, está presente também o sentimento de solidariedade e respeito mútuo para com o social mais amplo, uma vez que há também uma valorização da blitz como forma de evitar que condutores alcoolizados ameacem a integridade dos demais partícipes do trânsito. Conforme Freitas (2003), é importante, para o desenvolvimento da autonomia moral, que o jovem amplie seu universo de relações para além do convívio familiar e de amigos a fim de atingir ideais mais abrangentes de solidariedade e justiça.

Na discussão sobre o dilema do calçadão, que remete à atitude de um jovem diante de uma regra que não permite a circulação de ciclistas montados para a segurança das pessoas que ocupam determinado espaço como área de lazer, há um dado relevante sobre a importância de respeitar-se regras para uma boa convivência em espaços públicos. Segue o extrato:

Sol: O mais justo pra ele e para os outros seria ele respeitar a regra e ir pela ciclovia. [...] Indo pelo calçadão, ele poderia atropelar uma criança ou um idoso, se machucar e demorar mais ainda para voltar com o remédio. Só 
que, nesse caso, eu acho que ele escolheu o mais curto [...] pra se livrar

logo e voltar ao que estava fazendo. [...] Ele podia estar jogando videogame.

Nesse argumento, há consciência da importância do respeito à regra para a garantia da segurança de todos que transitam no calçadão, bem como para o sucesso da ação do protagonista em resposta à solicitação da mãe. Porém, na concepção de Sol, ele seguiu pelo caminho mais curto, descumprindo as regras para livrar-se da demanda e retornar ao que lhe interessava, evidenciando-se uma tendência ao individualismo, uma vez que ela demonstra considerar que as regras podem ser descumpridas por questões pessoais. Está implícito, nessa resposta, que a mãe representa a figura de autoridade na relação e que há um sentimento de respeito unilateral que obriga o protagonista a obedecê-la. Evidenciase, também, em sua concepção,

No que tange às questões debatidas neste subtema, as respostas remetem à compreensão das regras no plano da consciência, uma vez que o juízo recai majoritariamente sobre o princípio das normas e sobre as consequências para si e para os outros em caso de descumprimento. Em determinados momentos, fica implícito nas respostas o juízo de que é possível burlar a lei quando a situação envolve laços afetivos.

b) A sanção por multa como instrumento de justiça no trânsito:

A multa encontra-se no rol das penalidades do CTB e é a sanção mais aplicada em infrações de trânsito. Para este estudo, a multa é entendida como uma "punição material" (PIAGET, 1932/1994, p. 180), integrante do conjunto de sanções expiatórias, com finalidade de reparar um prejuízo causado. Porém, esse tipo de punição pode não ter relação com o ato da infração, sendo questionável sua eficácia em casos envolvendo prejuízos causados à vida de outrem, bem

Volume 11 Número 2 - Ago-Dez/2019

www.marilia.unesp.br/scheme 
como à mudança de comportamento no trânsito. Acredita-se que, em indivíduos mais heterônomos, a multa pode reforçar um comportamento transgressor na medida em que pese somente o prejuízo financeiro, visto que isso pode não ser um problema para certos infratores.

Para esta investigação, foram relevantes as respostas de Sol aos seguintes questionamentos: se a multa é uma forma justa de punir infratores de trânsito, se é capaz de mudar seus comportamentos, se haveria outras formas mais justas de puni-los e quais seriam estas formas. Quanto à primeira questão, o argumento mais relevante foi:

Sol: Se a pessoa brigar no trânsito, não é justo que seja multada. Se discutir, também não. Agora, [...] se bebeu e pegou o carro, aí eu acho que tem que multar [...]. Não sei se essa é a forma mais justa, porque é só pagar a multa e deu. [...] Que nem a moça que estacionou na vaga prioritária [dilema da vaga prioritária]: ela vai pagar a multa e pronto. [...] A multa não muda nada na pessoa. Não faz ela pensar no que fez. [...] Ainda mais aquelas pessoas que têm bastante dinheiro, essas aí, então, não estão nem aí para o valor das multas. É só mais uma conta para pagar.

A resposta evidencia a compreensão de que a multa não tem efeito algum se for vista pelo infrator como uma dívida a mais a ser paga dentre tantas outras, ou se o valor for irrisório, considerando que ele tenha um elevado poder aquisitivo. Quanto à possibilidade de existirem formas mais justas de punir infratores de trânsito, destaca-se a seguinte resposta:

Sol: Perder a carteira.

Entrevistadora: Em quais casos? 
Sol: Em qualquer caso. Tem que suspender a carteira. Tirar a pessoa do trânsito por um tempo. Acho que tem que ser assim. Porque, se receber multa, é só pagar de novo, e assim vai indo.

A escolha por determinada sanção pode obedecer a princípios de origens diversas. (PIAGET, 1932/1994). Portanto, seria necessário maiores informações para saber se essa resposta remete à compreensão de que a retirada do infrator do trânsito é vista como um castigo severo ou como forma de repensar seu comportamento. É possível que se trate de uma sanção por reciprocidade, já que no argumento anterior a afirmativa "não faz ela pensar no que fez" sugere que a reflexão é importante para a tomada de consciência sobre o erro cometido. Um questionamento sobre "qual poderia ser o efeito dessa sanção [recolhimento ou suspensão da habilitação] em infratores" poderia auxiliar na obtenção de mais elementos para a análise dessa questão.

A multa aparece nas respostas como principal instrumento de punição; porém, há uma preocupação em pensar outras sanções mais eficazes que levem infratores à reflexão e à tomada de consciência sobre o mal causado a outros no trânsito.

Com base na análise deste tema, que investiga se normas e sanções podem ser consideradas instrumentos de justiça no trânsito, pode-se inferir que as respostas oscilam entre a importância do cumprimento das normas como um dever legal e como forma de garantir um tratamento justo a todos os partícipes do trânsito, sendo as sanções de trânsito necessárias em ambos os casos, mas nem sempre eficazes na mudança de comportamento. 


\section{Sthìme \\ Revista Eletrônica de Psicologia e Epistemologia Genéticas}

\section{Considerações sobre o instrumento/roteiro de entrevista}

No estudo apresentado, destaca-se o processo de elaboração do roteiro de entrevista que, inspirado no Método Clínico (DELVAL, 2002), tem como objetivo reunir dados para a pesquisa de mestrado já mencionada. O processo envolve aprofundamento teórico, discussões em grupo e realização de estudos pilotos, etapa essencial na verificação da adequação do instrumento à temática e à faixa etária juvenil.

O roteiro de entrevista inicial era composto de questões de identificação, de investigação sobre o cotidiano de trânsito dos participantes e uma questão direta sobre o que entendem sobre justiça no trânsito. A partir do primeiro estudo piloto, foi possível identificar que algumas questões estavam mal elaboradas, considerando-se as orientações do Método Clínico (DELVAL, 2002), e outras fugiam do tema. Apresentado o piloto à banca de qualificação de projeto de pesquisa, algumas sugestões foram feitas no sentido de qualificar o roteiro, tais como o uso de dilemas, figuras e vídeos. A sugestão foi aceita, passando-se à elaboração das histórias que deram origem aos Dilemas e Rapidinhas.

Algumas questões do roteiro inicial sofreram ajustes a fim de evitar respostas como "sim" e "não", e outras irrelevantes foram excluídas. Sobre a elaboração dos Dilemas e Rapidinhas, ponderou-se que as histórias deveriam ser elaboradas de modo que mantivessem a coerência entre teoria e realidade, oportunizando ao adolescente colocar-se a partir de diferentes perspectivas no que tange às relações que se estabelecem no contexto de trânsito. Diante dessa complexidade, foram convidados a participar da construção dessas histórias profissionais da área de trânsito (psicólogos e pedagogos) e mestrandos da referida linha de pesquisa. 
Elaborada a segunda versão do instrumento, foram realizados mais dois estudos pilotos, dos quais decorreram novas necessidades de adequações, tanto na questão da linguagem, a fim de torná-la mais acessível ao adolescente, quanto na elaboração das questões. Tomou-se um cuidado especial com as questões de contra argumentação elaboradas durante as entrevistas, que, por serem improvisadas, nem sempre foram formuladas no sentido de incentivar o participante a expor sua compreensão sobre o tema abordado. Os problemas na elaboração de algumas questões não invalidam os estudos pilotos, mas cumprem a função de aperfeiçoar os processos.

A questão da contra argumentação elaborada com base na resposta do participante que se opôs à obstrução da rampa de acesso pela mãe que queria comprar o leite para o filho, na Rapidinha, foi um exemplo da necessidade de adequação. Na ocasião, perguntou-se: “e fazendo as compras bem rapidinho, ainda assim seria injusto?". Nesse caso, seria mais instigante perguntar da seguinte forma: “um colega teu disse que não haveria problema em estacionar obstruindo a rampa se a mãe fosse bem rapidinho ao mercado. O que pensas sobre isso?".

Outro exemplo ocorreu quando, ao longo da discussão sobre o Dilema da vaga prioritária, um dos participantes ajuizou que a pior consequência de estacionar na vaga seria a multa e o carro guinchado. Na ocasião, questionou-se: “essa seria a pior consequência da atitude dela [protagonista]?" Ao perguntar “qual seria a pior consequência da atitude dela?", abrir-se-ia a possibilidade de o participante colocar-se também da perspectiva da pessoa afetada.

Na reelaboração do roteiro, foram inseridas algumas questões de contra argumentação decorrentes dos estudos pilotos, ressalvadas as adequações, por seu potencial de nortear possíveis caminhos de discussão junto aos casos 
múltiplos. Após os ajustes realizados ao longo do processo de elaboração do roteiro, o instrumento de coleta de dados foi considerado adequado à investigação da noção de justiça no trânsito em adolescentes. Vislumbra-se a possibilidade de sua utilização em estudos sobre justiça no trânsito na perspectiva de adultos, ressalvadas as adequações das histórias a fim de aproximá-las à faixa etária.

Acredita-se, após o estudo preliminar apresentado, que a maioria das questões do roteiro estejam adequadas ao alcance dos objetivos da pesquisa de mestrado (compreender a noção de justiça de adolescentes), destacando-se três delas no sentido de que, por não envolverem somente normas explícitas no CTB, são mais relevantes ao estudo da noção de justiça, pois dependem tão somente do valor atribuído ao outro, à vida. São elas: as Rapidinhas que tratam da obstrução da rampa de acesso à calçada e do aviso WhatsApp sobre a blitz de trânsito e o Dilema do calçadão.

Destaca-se a importância da realização dos estudos pilotos não só por possibilitarem o aprimoramento do roteiro de entrevista e por apresentarem novos caminhos para a conquista dos objetivos da pesquisa, mas também por proporcionarem a experiência prática como entrevistador. Inicialmente, a condução da entrevista permaneceu mais centrada no roteiro. O contato com os adolescentes, o domínio das questões teóricas referentes ao tema e o aprofundamento de princípios definidores do Método Clínico proporcionados pelo exercício prático das entrevistas auxiliaram no desenvolvimento da autoconfiança e da habilidade na criação de novos desafios aos entrevistados.

Saber ouvir, apreender o sentido das ideias expresso na fala dos participantes e aproveitar as oportunidades de intervenção, formulando questões relevantes para além do roteiro básico sem influenciar nas respostas, é um exercício 


\section{Sthème \\ Revista Eletrônica de Psicologia e Epistemologia Genéticas}

difícil, porém essencial à prática de entrevistas que buscam aproximação com o Método Clínico.

\section{Considerações finais}

Entende-se, com base no referencial escolhido, que não basta a obediência literal das normas para ser uma pessoa justa no trânsito. Freitas (2003, p. 62) destaca que "não basta agir conforme o dever para que nosso ato tenha um valor moral. Pode-se agir conforme o dever para obter um benefício, por medo da punição ou por vergonha, ou ainda, por prazer". O real valor de uma ação está nos motivos pelos quais uma pessoa cumpre seu dever social.

Sendo assim, entende-se que é justo no trânsito aquele que reconhece a presença do outro e o valoriza como ser humano. Segundo Freitas (2002), isso se torna possível à medida que uma pessoa atribui à escala de valores de outra um valor equivalente ao valor da própria escala. Desta forma, o respeito mútuo - que, na concepção de Piaget (1932/1994), exige reciprocidade, solidariedade e cooperação - passa a ser condição para a justiça no trânsito.

Essa ideia de justiça com base na valorização do outro, na reciprocidade, na solidariedade e na cooperação, aplicada ao contexto das relações interpessoais no trânsito urbano de Porto Alegre, foi fundamental para a criação das situações apresentadas no roteiro de entrevista e para a análise das respostas decorrentes dele.

A apropriação do método de estudo de caso nos moldes propostos por Yin (2015); o processo de construção do roteiro de entrevista inspirado no Método Clínico conforme apresentado por Delval (2002); a leitura de autores que utilizaram esse método, como Amaral (2017), Freiesleben, Becker e Loder (2017), Nunes (2018), Becker e Rodrigues (2018); e a participação ativa da autora como entrevistadora durante os três estudos pilotos favoreceram o seu desenvolvimento como 
pesquisadora e o aprofundamento da compreensão da noção de justiça presente nas respostas do caso investigado.

Acredita-se que o roteiro aqui apresentado está alinhado aos objetivos da pesquisa e pronto para ser aplicado aos casos múltiplos. Poderá, também, inspirar a elaboração de outros instrumentos sobre o estudo da noção de justiça para contextos diferenciados, como, por exemplo, o escolar.

Quanto à noção de justiça presente nas respostas analisadas, foi possível verificar que grande parte dos argumentos expressam um movimento inicial de descentração do pensamento no que tange à justiça nas relações interpessoais de trânsito. Mesmo que em determinados momentos o juízo heterônomo tenha tomado espaço nas decisões exigidas pelos Dilemas e Rapidinhas, a maioria das respostas demonstra certa tendência à reciprocidade, ao respeito mútuo e à solidariedade para com o outro no trânsito, expressando certa autonomia do pensamento.

Identifica-se nas respostas uma preocupação em garantir os direitos iguais de todos no trânsito mediante o cumprimento das normas, em especial os direitos daqueles que necessitam um tratamento diferenciado, a exemplo dos cadeirantes.

Quanto à responsabilidade, percebe-se, nas respostas analisadas, a presença da perspectiva subjetiva, atribuída ao próprio infrator, nos casos de condutas desconformes com as regras. Segundo a jovem, na maioria das situações apresentadas não há espaço para desculpas quando se trata de garantia de direitos no trânsito, exceto quando implicam defender um familiar ou amigo.

As sanções de trânsito são consideradas e valorizadas pela entrevistada, e as mais abordadas apresentam características expiatórias. Embora apareça 
a ideia de que é preciso pensar em formas de sanção capazes de mudar comportamentos através da tomada de consciência, a multa é vista como necessária para quem comete infrações e causa prejuízo ao outro, ainda que não seja considerada um instrumento eficaz de justiça no trânsito.

Diante do exposto, pode-se concluir que os argumentos apresentados neste estudo de caso transitam entre a noção de justiça retributiva e a noção de justiça distributiva, com maior incidência nesta última. Portanto, entende-se que a maioria das respostas apresenta descentração e reflexão compatíveis com a transição da heteronomia para a autonomia e da ênfase na igualdade para a busca de equidade no juízo moral. Em geral, o direito do outro à segurança e ao tratamento justo no trânsito aparece nas respostas e está acima das expectativas individuais, demonstrando que há coordenação de perspectivas, valorização do outro e interesse no bem coletivo, ainda que em alguns momentos esteja presente um juízo centrado no bem-estar do grupo afetivo (sociocentrismo).

Considera-se que os resultados deste estudo são esclarecedores na compreensão da trajetória do pensamento da adolescente em questão e do desenvolvimento de sua noção de justiça no trânsito. Eles abrem possibilidades de análise para os casos múltiplos e para a busca de uma generalização analítica das proposições teóricas que embasam a investigação. (YIN, 2015). Espera-se que esses resultados contribuam para o debate sobre a temática abordada e sobre as possibilidades de aprendizado e utilização das contribuições do Método Clínico na pesquisa qualitativa com entrevistas. 


\section{Referências}

AMARAL, C. B. Estratégias pedagógicas para o ensino fundamental: um enfoque na dimensão socioafetiva. 2017. 255 f. Tese (Doutorado em Educação) -- Programa de PósGraduação em Educação, Universidade Federal do Rio Grande do Sul (UFRGS), Porto Alegre, 2017. Disponível em: 〈https://bit.ly/2TpcnoS〉. Acesso em: 21 dez. 2018.

BECKER, M. R.; RODRIGUES, T. C. A Contribuição de Piaget e a Experiência Prática: Um Estudo de Caso sobre a Formação do Professor de Educação Infantil. Schème: Revista Eletrônica de Psicologia e Epistemologia Genéticas, Marilia, v. 10, n. 2, p. 159187, 2018.

BRASIL. Resolução n ${ }^{0}$ 510, de 07 de abril de 2016, Dispõe sobre as normas aplicáveis a pesquisas em Ciências Humanas e Sociais. Diário Oficial [da] República Federativa do Brasil, Brasília, DF, 24 maio 2016. Disponível em: <http://bvsms.saude.gov.br/bvs/saudelegis/cns/2016/res0510_07_04_2016.html >. Acesso em: 20 jun. 2019.

CORASSA, N. Seu carro, sua casa sobre rodas: que tipo de motorista você é? Curitiba: Juruá, 2011.

DELL'AGLIO, D. D.; HUTZ, C. S. Padrões evolutivos na utilização dos princípios de justiça distributiva em crianças e adolescentes no sul do Brasil. Psicologia: Reflexão e Crítica, Porto Alegre, v. 14, n. 1, p. 97-106, 2001.

DELVAL, J. Introdução à prática do método clínico: descobrindo o pensamento das crianças. Porto Alegre: Artmed, 2002.

FREIESLEBEN, F. B.; BECKER, M. L. R.; LODER, L. L. Uma Metodologia de Pesquisa sobre a Construção de Conhecimentos em Circuitos Elétricos Lineares Elaborada com Base no Método Clínico Piagetiano. Revista Brasileira de Pesquisa em Educação em Ciências, Minas Gerais, v. 17, n. 3, p. 1011-1035, dez. 2017.

FREITAS, L. B. L. Autonomia moral na obra de Jean Piaget: a complexidade do conceito e sua importância para a educação. Educar em Revista, Curitiba, n. 19, p. 11-22, jun. 2002. Disponível em: <encurtador.com.br/bsHO7 >. Acesso em: 19 ago. 2019.

Do mundo amoral à possibilidade de ação moral. Psicologia Reflexão e Crítica, Porto Alegre, v. 12, n. 2, p. 447-458, 2003.

GUEDES, J. C. O.; PASCUAL, J. G. Mediação de Conflitos e Julgamento de Dilemas Morais: Contribuições da Psicologia Genética à Educação. Schème: Revista Eletrônica de Psicologia e Epistemologia Genéticas, Marília, v. 8, n. 16, p. 161-188, 2016.

Volume 11 Número 2 - Ago-Dez/2019

www.marilia.unesp.br/scheme 
JORGE, M. H. P. M.; MARTINS, C. B. G. A criança, o adolescente e o trânsito: algumas reflexões importantes. Revista Associação Medicina Brasileira. São Paulo, v. 59, n. 3, p. 199-208, 2013.

KESSELRING, T. Ética, política e desenvolvimento humano: a justiça na era da globalização. Caxias do Sul, RS: Educs, 2007.

. Jean Piaget. Petrópolis: Vozes, 1993.

LA TAILLE, I. A escola e os valores: a ação do professor. In: LA TAILLE, I.; PEDROSILVA, N.; JUSTO, J. S. Indisciplina/disciplina: ética, moral e ação do professor. 5. ed. Porto Alegre: Mediação, 2013.

Moral e ética no mundo contemporâneo. Revista USP, São Paulo, n. 110, p. 2942, jul./ago./set. 2016.

Moral e ética. Porto Alegre: Artmed, 2006.

Summus, 1994.

Prefácio. In: PIAGET, J. [1932]. O Juízo Moral na Criança. São Paulo:

MENIN, M. S.; BATAGLIA, P. U. R.; MORO, A. Adesão ao valor justiça em crianças e adolescentes. Estudos em avaliação educacional, São Paulo, v. 24, n. 56, p. 18-47, set./dez., 2013. Disponível em: <encurtador.com.br/flqM5>. Acesso em: 11 nov. 2018.

NUNES, A. P. O processo de ensino e aprendizagem em administração: ação cognitiva dos alunos na perspectiva do professor. 2018. $111 \mathrm{f}$. Dissertação (Mestrado em Educação) -- Programa de Pós-graduação em Educação, Universidade Federal do Rio grande do Sul (UFRGS), Porto Alegre, 2018.

PIAGET, J. Epistemologia genética. Tradução Álvaro Cabral. 3. ed. São Paulo: Martins Fontes, 2007.

[1964]. Estudos Sociológicos. Rio de Janeiro: Forense, 1973.

[1932]. O Juízo Moral na Criança. São Paulo: Summus, 1994.

[1953]. Relações entre a afetividade e a inteligência no desenvolvimento mental da criança. Rio de Janeiro: Wak, 2014.

SALES, E. M. B. O conceito de justiça distributiva relacionado às normas sociais escolares. Psicologia: Reflexão e Crítica, Porto Alegre, v. 13, n. 1, p. 49-58, 2000. Disponível em: <encurtador.com.br/mFGMR>. Acesso em: 1 fev. 2018.

Volume 11 Número 2 - Ago-Dez/2019

www.marilia.unesp.br/scheme 
SAMPAIO, L. R.; CAMINO, C. P. S.; ROAZZI, A. Justiça distributiva em crianças de 5 a 10 anos de idade. Psicologia: Reflexão e Crítica, Porto Alegre, v. 20, n. 2, p. 197 204, 2007.

SCHÜNEMANN, H. E. S et al. A compreensão de crianças e adolescentes a respeito da trapaça. Revista Eletrônica de Psicologia e Epistemologias Genéticas, São Paulo, v. 8, n.1, p. 98-121, jan./jul., 2016.

YIN, R. K. Estudo de caso: planejamento e métodos. Porto Alegre: Bookman, 2015.

Recebido em: 04/10/2019

Aprovado em: 11/01/2020 